University of Nebraska - Lincoln

DigitalCommons@University of Nebraska - Lincoln

Faculty Publications from the Harold W. Manter Laboratory of Parasitology

1999

Evolutionary Relationships among the Protostrongylidae (Nematoda: Metastrongyloidea) as Inferred from Morphological Characters, with Consideration of Parasite-Host Coevolution

\author{
Ramon A. Carreno \\ University of Guelph \\ Eric P. Hoberg \\ United States Department of Agriculture, Agricultural Research Service, geocolonizer@gmail.com
}

Follow this and additional works at: https://digitalcommons.unl.edu/parasitologyfacpubs

Part of the Evolution Commons, and the Parasitology Commons

Carreno, Ramon A. and Hoberg, Eric P., "Evolutionary Relationships among the Protostrongylidae (Nematoda: Metastrongyloidea) as Inferred from Morphological Characters, with Consideration of Parasite-Host Coevolution" (1999). Faculty Publications from the Harold W. Manter Laboratory of Parasitology. 731.

https://digitalcommons.unl.edu/parasitologyfacpubs/731

This Article is brought to you for free and open access by the Parasitology, Harold W. Manter Laboratory of at DigitalCommons@University of Nebraska - Lincoln. It has been accepted for inclusion in Faculty Publications from the Harold W. Manter Laboratory of Parasitology by an authorized administrator of DigitalCommons@University of Nebraska - Lincoln. 


\title{
EVOLUTIONARY RELATIONSHIPS AMONG THE PROTOSTRONGYLIDAE (NEMATODA: METASTRONGYLOIDEA) AS INFERRED FROM MORPHOLOGICAL CHARACTERS, WITH CONSIDERATION OF PARASITE-HOST COEVOLUTION
}

\author{
Ramon A. Carreno and Eric P. Hoberg* \\ Department of Environmental Biology, University of Guelph, Guelph, Ontario, Canada N1G 2W1
}

\begin{abstract}
The phylogeny of nematodes in the family Protostrongylidae (Nematoda: Metastrongyloidea) was reconstructed by cladistic analysis of 28 binary and multistate characters derived from comparative morphology. Analyses were hierarchical, and examined (1) relationships among genera, including 13 ingroup taxa and Metastrongylidae as an outgroup (single tree, 78 steps, consistency index $[\mathrm{CI}]=0.705$ ); and $(2)$ relationships among genera and species groups, including 21 ingroup taxa and Metastrongylus apri as an outgroup (single tree, 76 steps, $\mathrm{CI}=0.582$ ). In the species-level tree, Protostrongylidae was divided into 2 major clades, 1 containing the subfamilies Muelleriinae (including the recently described Umingmakstrongylus pallikuukensis), Elaphostrongylinae, and the Varestrongylinae (excluding Pneumocaulus kadenazii). Varestrongylus was paraphyletic as it included Pneumostrongylus calcaratus. The second major clade consisted of a paraphyletic group containing Protostrongylus spp. and Spiculocaulus leuckarti and, basal to this subclade, several other individual protostrongylid lineages. The various subclades generally correspond to the subfamilial divisions of the Protostrongylidae. The Neostrongylinae, however, is not supported as Neostrongylus and Orthostrongylus are not sister groups. Based on a large number of hypothesized synapomorphies, the elaphostrongylines appear to be a highly derived group of protostrongylids, a feature potentially correlated with their habitat localization in muscular and nervous tissues. The generic-level tree retained most of the primary structure revealed among the species but excluded the varestrongylines from the Muelleriinae + Elaphostrongylinae subclade. Artiodactyles of the family Cervidae are considered basal hosts for protostrongylids; secondary colonization in Caprini, Rupicaprini, and among lagomorphs is postulated.
\end{abstract}

Nematodes of the Protostrongylidae Leiper, 1926 include predominantly lung-inhabiting parasites, many of which are serious pathogens in wild and domestic ruminants and lagomorphs. Adults and first-stage larvae of most protostrongylids form nodules in the lungs that can lead to respiratory distress and secondary bacterial infection resulting in verminous pneumonia (e.g., Demartini and Davies, 1977; Svarc, 1984; Sauerländer, 1988; Costantini et al., 1990; Mansfield et al., 1993; Pajersky, 1995). Lungworm infections with species of Protostrongylus Kamensky, 1905 are among the most important diseases of Rocky Mountain bighorn sheep (Hibler et al., 1982). Protostrongylids in Elaphostrongylus Cameron, 1931 and Parelaphostrongylus Boev and Schulz, 1950 are also serious pathogens in cervids. Members of both genera occur in the skeletal muscles and nervous system, and Parelaphostrongylus tenuis (Dougherty, 1945) is responsible for neurologic disease in North American moose and potentially in many wild and farmed ruminants including cervids and camelids (e.g., Anderson, 1964, 1971; Nettles et al., 1977; Brown et al., 1978; Guthery et al., 1979; Tyler et al., 1980; Krogdahl et al., 1987; Lankester and Fong, 1989), whereas species of Elaphostrongylus are of similar importance in Eurasian cervids and other hosts (Roneus and Nordkvist, 1962; Prosl and Kutzer, 1980; Handeland and Norberg, 1992; Handeland and Skorping, 1992, 1993). Thus, the protostrongylids have been known for a long time as important disease agents in wild, farmed, and domestic ruminants.

The genera of Protostrongylidae are distinguished from other metastrongyloids in having a well developed gubernaculum and telamon apparatus (Boev, 1975; Anderson, 1978, 1992; Lichtenfels, 1987). All species for which life cycles are known have

Received 30 October 1998; revised 15 January 1999; accepted 15 January 1999.

* United States Department of Agriculture, Agricultural Research Service, Biosystematics and National Parasite Collection Unit, BARC East No. 1180, 10300 Baltimore Avenue, Beltsville, Maryland 20705. a gastropod intermediate host in which infective third-stage larvae develop. Differentiation of adults is based primarily on the morphology of the spicules, gubernaculum, telamon, and vulva. Differences in bursal morphology, particularly in the shape and number of branches of the dorsal ray, have also been applied. These characters were used by Boev (1975) in his designation of various subfamilies in the Protostrongylidae (Table I). This classification was based on comparative morphology among genera but did not explicitly develop hypotheses for phylogenetic relationships in the group.

Little is known about the evolutionary and biogeographic history of the Metastrongyloidea and Protostrongylidae, and these taxa have not been evaluated phylogenetically as have other groups such as the Trichostrongyloidea and Trichostrongylidae (e.g., Durette-Desset, 1985; Hoberg and Lichtenfels, 1994). Within the Metastrongyloidea, the Protostrongylidae were believed by Dougherty (1949) to be part of a lineage that included the Filaroidinae and Pseudaliinae. He suggested that these 3 lineages corresponded, respectively, to radiations in carnivores, cetaceans, and artiodactyles. Pryadko (1984) (as in Lichtenfels, 1987) proposed that protostrongylids were archaic and considerably older than reptiles and mammals and that metastrongyloids were originally parasites of amphibians.

Within the Protostrongylidae, there have been no prior phylogenetic interpretations for the evolution of the family, and relationships among the genera are unknown. Although phylogenetic analyses exist for elaphostrongyline nematodes (Platt, 1984; Carreno and Lankester, 1994), the evolution of this clade relative to other protostrongylids has remained unclear. In addition, the recent discovery and diagnosis of a new protostrongylid genus, Umingmakstrongylus Hoberg, Polley, Gunn, and Nishi, 1995 in North American muskoxen, have raised the question of how this parasite is related to other protostrongylids (Hoberg et al., 1995). In this analysis we provide a phylogenetic hypothesis for the Protostrongylidae obtained using morphological characters. The results of this phylogenetic reconstruction 
Table I. Classification of the Protostrongylidae Leiper, 1926.*

Subfamily Elaphostrongylinae Boev and Schulz, 1950

Genera: Elaphostrongylus Cameron, 1931, Parelaphostrongylus Boev and Schulz, 1950

Subfamily Muelleriinae Skrjabin, 1933

Genera: Muellerius Cameron, 1927; Cystocaulus Schulz, Orlow, and Kutass, 1933; Umingmakstrongylus Hoberg, Polley, Gunn, and Nishi, 1995

Subfamily Neostrongylinae Boev and Schulz, 1950

Genera: Neostrongylus Gebauer, 1932; Orthostrongylus Dougherty and Goble, 1946

Subfamily Protostrongylinae Kamensky, 1905

Genera: Protostrongylus Kamensky, 1905; Spiculocaulus Schulz, Orlow, and Kutass, 1933

Subfamily Skrjabinocaulinae Boev and Sulimov, 1963

Genus: Skrjabinocaulus Boev and Sulimov, 1963

Subfamily Varestrongylinae Boev, 1968

Genera: Varestrongylus Bhalerao, 1932; Pneumostrongylus Mönnig, 1932; Pneumocaulus Schulz and Andreeva, 1948

* After Boev (1975), with modification of the Muelleriinae Skrjabin, 1933 by Hoberg et al. (1995).

are a test of the validity of various taxonomic classifications of the protostrongylids and provide a basis for future systematic studies within the family. Additionally, we explore the putative history for parasite-host relationships for the protostrongylids, artiodactyles, and lagomorphs within a phylogenetic context for these nematodes.

\section{MATERIALS AND METHODS}

\section{General methods and specimens}

Representative specimens of each of the genera of the Protostrongylidae were examined to acquire an understanding of the diversity and homology for structural characters across the family; at least 1 representative of each genus was studied, and this information was augmented by detailed descriptions in the literature (Table II). Specimens were obtained from the United States National Parasite Collection, the Canadian Museum of Nature, Division of Invertebrates, the University of Alberta parasite collection, and from the authors' personal collections. It was not possible to obtain specimens of Spiculocaulus leuckarti Schulz, Orloff, and Kutass, 1933, Skrjabinocaulus sofievi Boev and Sulimov, 1933, Pneumocaulus kadenazii Schulz and Andreeva, 1948, and Neostrongylus linearis (Marotel, 1913). For these species, information was obtained from published descriptions (Table II). A total of 28 binary and multistate characters was defined.

\section{Phylogenetic analysis}

Higher-level analyses of supraspecific taxa in the Metastrongyloidea have not been conducted, and thus it was problematic to determine the sister group and maximally informative outgroups for the Protostrongylidae. Although the Metastrongyloidea are presently unresolved, there is substantial evidence that the Metastrongylidae (and species of Metastrongylus Molin, 1861) are basal in the superfamily. Species of Metastrongylus have well developed cephalic labia, a simple gubernaculum (sometimes absent), and a unique structure for bursal rays (Dougherty, 1949). Additionally, they are oviparous and the egg-shell is thick (Anderson, 1978). Furthermore, members of this genus occur exclusively in suids and use earthworms as intermediate hosts rather than gastropods as in most other groups including the Protostrongylidae. These features provide sufficient evidence that Metastrongylidae is distinct from other groups, and it is generally believed to be basal to the other major families in the Metastrongyloidea (Dougherty, 1949; Lichtenfels, 1987; Durette-Desset et al., 1994). Consequently, based on this justification, Metastrongylidae and Metastrongylus apri, respectively, were designated as outgroups for hierarchical analysis of genera and species of Protostrongylidae in the present study. Additionally, attempts to resolve relationships of the Protostrongylidae were also examined relative to genera and species of Crenosomatidae Schulz, 1951 and Skrjabingylidae (Skrjabin, 1933).

Character polarity was determined relative to the taxonomic outgroups as specified above. Separate data matrices for generic and species-level taxa were written using MacClade 3.05 (Maddison and Maddison, 1992) and included 28 binary and multistate characters (Tables III and IV). In the generic-level matrix certain characters were coded as polymorphic to recognize interspecific variation in an attribute among species in a genus (multistate taxa) (Table IV). The data matrices were analyzed using the software Phylogenetic Analysis Using Parsimony (PAUP), version 3.1.1 (Swofford, 1993) first in a heuristic search mode with variation in options for branch swapping, e.g., TBR, SPR, NNI, with Addition Sequence $=$ Simple and with MULPARS in effect; multistate characters were unordered. Trees were confirmed with Branch and Bound, a more exact algorithm for obtaining the most parsimonious solution. Descriptive statistics include the consistency index (CI), homoplasy index (HI), and retention index (RI). Host associations for protostrongylid genera and species were examined by mapping and optimization of mammalian taxa onto the parasite phylogeny with MacClade 3.05 (Maddison and Maddison, 1992).

\section{RESULTS}

\section{Character descriptions}

1. First stage larva, tail: blunt tail $=0$; dorsal spine on tail $=$ 1 ; long and tapering tail ending in a spiked tip $=2$.

2. Provagina: absent $=0$; small cuticular projection over vulva $=1$; large ventral flap extending close to or up to the tail tip attached to body by thin folds of cuticle $=2$; cylindrical $=3$; several flaps $=4$.

3. Gubernaculum, crura: crura absent $=0$; crura small, smooth, and round $=1$; rod shaped and smooth $=2$; rod shaped and with projections or ridges $=3$; in the form of plates with large, often sharp (pointed) projections $=4$; in the form of plates with small projections $=5$.

4. Telamon: absent $=0$; telamon consisting of simple basal and transverse plates $=1$; consisting of several shieldlike plates $=2$; a small distal plate forming a pear-shaped or heart-shaped structure $=3$; complex and consisting of many plates $=4$; consisting of 2 crescentic, sagittally symmetrical parts $=5$.

5. Capitulum: absent $=0$; present with 2 spikes or "ears" sensu Boev $(1975)=1 ; 4$ or more spikes present $=2$. 
TABLE II. Protostrongylid species examined in this study, listed by putative subfamily according to Boev (1975); Metastrongylidae represents the outgroup for analysis.*

METASTRONGYLIDAE

Metastrongylus apri (Gmelin, 1790) Vostokov, 1905: NMCP1984-0237, acc. 1981-140; USNPC 76946

\section{PROTOSTRONGYLIDAE}

Elaphostrongylinae

Elaphostrongylus cervi Cameron, 1931: personal collection (R.A.C.)

Parelaphostrongylus odocoilei (Hobmaier and Hobmaier, 1934) Boev and Schulz, 1950: description in Carreno and Lankester (1993); personal collection (R.A.C.)

\section{Varestrongylinae}

Varestrongylus alpenae (Dikmans, 1935) Dougherty, 1945: USNPC 34066 (holotype), USNPC 78599 (voucher)

Varestrongylus pneumonicus Bhalerao, 1932: USNPC 45199

Varestrongylus sagittatus (Mueller, 1890) Dougherty, 1945: USNPC 37855

Pneumostrongylus calcaratus Mönnig, 1932: USNPC 65889 (voucher)

Pneumocaulus kadenazii Schulz and Andreeva (1948): description in Schulz and Andreeva (1948)

Muelleriinae

Muellerius capillaris (Mueller, 1889) Cameron, 1927: USNPC 45386 (voucher)

Umingmakstrongylus pallikuukensis Hoberg, Polley, Gunn, and Nishi, 1995: CMNPA1995-0040 and 0041 (holotype and allotype); CMNPA1995-0043, acc. A1995.0035 (paratype); USNPC 84826 (paratypes)

Cystocaulus nigrescens (=ocreatus) (Railliet and Henry, 1907) Mikacic, 1939: USNPC 37845; personal collection (R.A.C.)

Neostrongylinae

Neostrongylus linearis (Marotel, 1913) Gebauer, 1932: descriptions in Gebauer (1932), Kreis (1944), Rojo-Vazquez and Cordero del Campillo (1974), Castañon Ordoñez et al. (1984)

Orthostrongylus macrotis (Dikmans, 1931) Dougherty and Goble, 1946: USNPC 65929, 76738, 43679, 43610, 30418

Protostrongylinae

Protostrongylus boughtoni Goble and Dougherty, 1943: University of Alberta Parasite Collection (UAPC 10796); personal collection

(R.A.C.)

Protostrongylus hobmaieri (Schulz, Orlow, and Kutass, 1933) Cameron, 1934: USNPC 37839

Protostrongylus pulmonalis (Frölich, 1802) Goble and Dougherty, 1943: description in Costantini et al. (1990)

Protostrongylus raillieti (Schulz, Orlow, and Kutass, 1933) Cameron, 1934: USNPC 37831

Protostrongylus rufescens (Leuckart, 1865) Kamensky, 1905: USNPC 46516

Protostrongylus rushi Dikmans, 1937: USNPC 66043, 78423

Protostrongylus stilesi Dikmans, 1931: USNPC 66044, 66045, 49227, 59749

Spiculocaulus leuckarti Schulz, Orlow, and Kutass, 1933: description in Schulz et al. (1933)

Skrjabinocaulinae

Skrjabinocaulus sofievi Boev and Sulimov, 1963: description in Boev and Sulimov (1963)

* In addition to morphological descriptions in Boev (1975), the following museum specimens and published descriptions were studied for character information. Specimen lots designated as NMCP and CMNP are from the Canadian Museum of Nature, Ottawa; those designated USNPC are from the United States National Parasite Collection, Beltsville, Maryland.

TABLE III. Data matrix generated by using Metastrongylidae as an outgroup in assessing characters for generic-level taxa in the Protostrongylidae.

\begin{tabular}{ll}
\hline \multicolumn{1}{c}{ Taxa } & \multicolumn{1}{c}{ Characters 1-28* } \\
\hline Metastrongylidae & $0000000010 ? 0000001000000 ? 000$ \\
Muellerius & $1101020100 ? 00011000000000113$ \\
Pneumocaulus & $12451100101000000 ? ? 0010 ? 1011$ \\
Neostrongylus & 1312121010000000010012001011 \\
Skrjabinocaulus & $1010110000 ? ? ? 1000 ? ? 0 ? 20 ? ? 012$ \\
Pneumostrongylus & 1323000101000000010001001011 \\
Elaphostrongylus & 1000020000011000100100100013 \\
Parelaphostrongylus & 1040020100011000100101101013 \\
Varestrongylus & $13 \& 440 \& 300 \& 20111000000010001001011 \& 3$ \\
Orthostrongylus & 2014211000200100011002002011 \\
Cystocaulus & 1323120100100011010012011113 \\
Umingmakstrongylus & 1023100100100011010012011113 \\
Spiculocaulus & $? 32511100010000001 ? 0 ? 2002011$ \\
Protostrongylus & $20 \& 1 \& 2 \& 32 \& 351 \& 21 \& 21000100100010 \& 1002002011$ \\
\hline
\end{tabular}

* Missing data indicated by ?; polymorphism in multistate taxa by $\&$. 


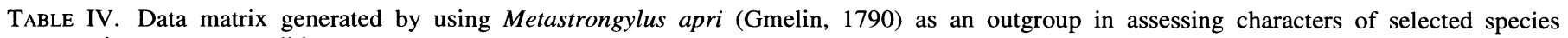
representing protostrongylid taxa.

\section{Taxa}

Metastrongylus apri

Muellerius capillaris

Pneumocaulus kadenazii

Neostrongylus linearis

Pneumostrongylus calcaratus

Elaphostrongylus cervi

Parelaphostrongylus odocoilei

Varestrongylus pneumonicus

Varestrongylus alpenae

Varestrongylus sagittatus

Orthostrongylus macrotis

Cystocaulus ocreatus

Umingmakstrongylus pallikuukensis

Spiculocaulus leuckarti

Protostrongylus rufescens

Protostrongylus boughtoni

Protostrongylus stilesi

Protostrongylus hobmaieri

Protostrongylus raillieti

Protostrongylus rushi

Protostrongylus pulmonalis
Characters $1-28 *$

$0000000010 ? 0000001000000 ? 000$

$1101020100 ? 00011000000000113$

$12451100101000000 ? ? 0010 ? 1011$

1010110000 ??? 1000 ? ?0?20??012

1323000101000000010001001011

1000020000011000100100100013

1040020100011000100101101013

1443000111000000010001001011

1340020111000000010001001013

$13430001110000000 ? ? 001001011$

2014211000200100011002002011

1323120100100011010012011113

1023100100100011010012011113

?32511100010000001?0?2002011

2035221000100100010002002011

2225211000100100001002002011

2335211000100100010002002011

$212511100010010001 ? 002002011$

2235221000100100010002002011

2235211000100100010002002011

2025211000100100000002002011

* Missing data indicated by ?.

6. Bursa: split $=0$; slightly notched dorsally $=1$; undivided $=2$.

7. Dorsal ray: either absent or, if present, elongate $=0$; distinctly spherical $=1$.

8. Spicule shaft: distally unbranched $=0$; distally branched $=1$.

9. Posterolateral rays: equal in length to other rays $=0$; shorter than other lateral rays $=1$.

10. Ventral rays: common stalk of ventral rays short $=0$; joined by a long and thick common stalk $=1$.

11. Structure of gubernaculum: crura short relative to corpus, proximal part of corpus unpaired $=0$; crura long relative to corpus, proximal part of corpus paired $=1$; crura short relative to corpus, proximal part of corpus paired $=2$.

12. Excretory pore: at midregion or posterior half of esophagus $=0$; at anterior half of esophagus $=1$.

13. Nerve ring: surrounding esophagus at a point in its posterior $3 / 4=0$; at its anterior $1 / 4=1$.

14. Spicule tips: tip of spicule shaft pointed, sharp $=0$; tip blunt $=1$.

15. Spicule shaft: unjointed $=0$; with a joint at midlevel of shaft $=1$.

16. Spicule ribs: spicules without ctenidia-like ribs near tip of main shaft $=0$; ctenidia-like ribs present $=1$.

17. Shape of eggs: eggs oval or elliptical $=0$; eggs spherical $=1$.

18. Muscle radiations at bursa: strong visible cuticular or muscular radiations associated with copulatory structures absent $=0$; strong cuticular or muscular radiations present $=1$.

19. Buccal opening: without interior "lips" = 0 ; containing three inward pointing lips $=1$.

20. Shape of cephalic extremity: blunt $=0$; rounded $=1$.
21. First stage larva, tail: tail tip uniform $=0$; tip made up of 2 or 3 segments $=1$.

22. Crura, attachment to corpus: no crura attached to corpus $=$ 0 ; crura of different density than corpus or unattached to corpus $=1$; crura of similar density and fused to corpus by the proximal ends $=2$.

23. Female tail: tip in the form of an acute (sharp) cone $=0$; in the form of an obtuse (blunt) cone $=1$.

24. Membranes on crura: distal part of crura not surrounded by a thick membrane $=0$; surrounded by a colorless, lightrefracting membrane $=1$.

25. Gubernaculum, corpus: corpus in the form of a simple, compact plate $=0$; in the form of an elongate, narrow plate $=1$; in the form of 2 cords sometimes united through a less compact tissue $=2$.

26. Dorsal ray, branching: dorsal ray not trilobed $=0$; trilobed $=1$.

27. Unpaired pedunculate dorsal papilla: absent $=0$; present $=1$.

28. Dorsal ray division: short and divided $=0$; short and undivided $=1$; long and undivided $=2$; long and divided $=3$.

\section{Phylogenetic analysis}

Analysis at the generic level in Protostrongylidae resulted in a single most parsimonious tree (MPT; 78 steps; CI $=0.705$; $\mathrm{CI}$, excluding uninformative characters $=0.614 ; \mathrm{HI}=0.436$; $\mathrm{RI}=0.676$ ) that diagnoses monophyly for the family based on characters 1, 4, 8, 27, and 28. (Fig. 1); diagnostics for individual characters are shown in Table V. Homoplasy was associated with 11 characters (parallelism/convergence for chars. 2, 3, 5, $6,8,9,11,21$, and 25 ; reversal for $6,7,8,11$, and 18). In the fully resolved MPT, 2 major clades are diagnosed: (1) a sister- 


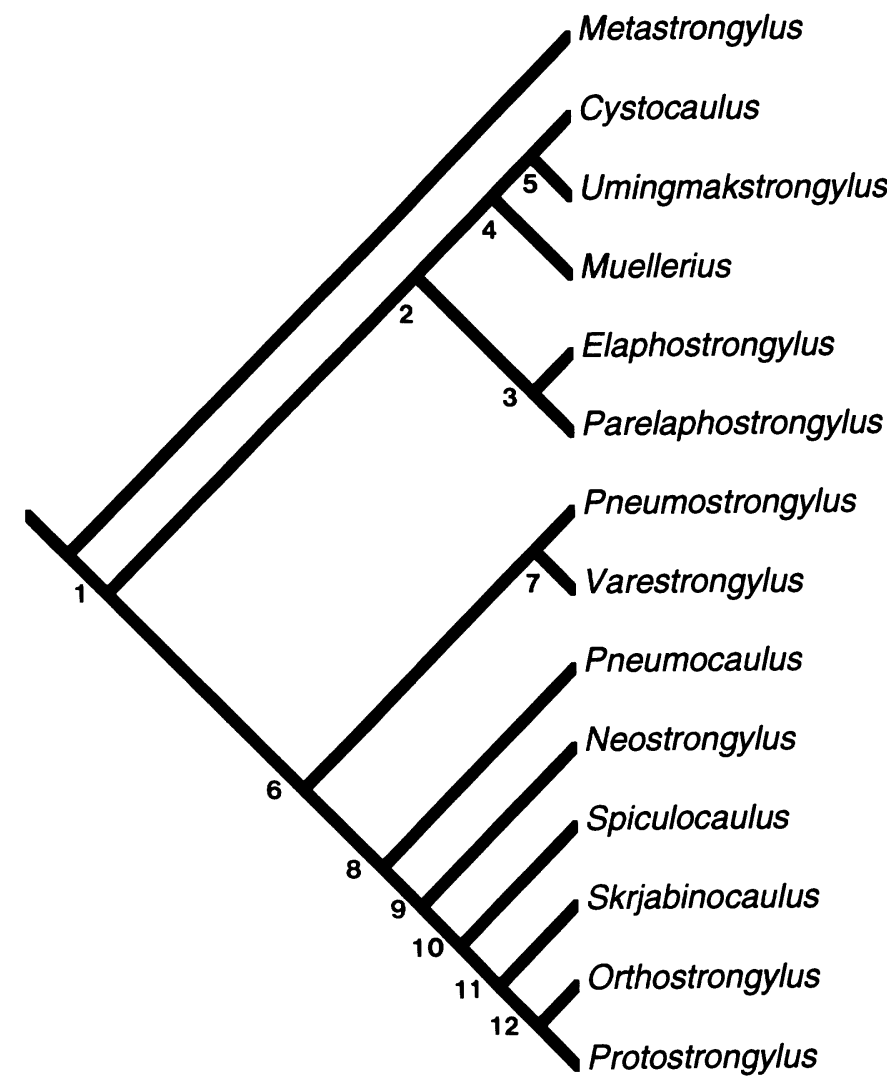

FIGURE 1. Phylogenetic relationships for genera of the family Protostrongylidae Leiper, 1926 as inferred by parsimony analysis of characters derived from studies of comparative morphology. Represented is the single most parsimonious tree $(\mathrm{CI}=0.705)$. Character support for terminal taxa and internodes is defined below (nodes are numbered) and includes apomorphy (A), homoplasy as convergence or parallelism $(\mathrm{H})$ and reversal $(\mathrm{R})$, and polymorphic change in terminal taxon $(\mathrm{P})$. Terminal taxa are labeled according to generic-level nomenclature: outgroup, Metastrongylidae and Metastrongylus; ingroup: Cystocaulus $(\mathrm{H}$ : 2); Umingmakstrongylus (R: 6); Muellerius (A: 2, 4; H: 25); Elaphostrongylus (H: 25; R: 8); Parelaphostrongylus (H: 3, 22); Pneumostrongylus (A: 3; H: 9); Varestrongylus (without diagnostic characters; P: 2, 4, 6); Pneumocaulus (A: 2); Neostrongylus (A: 4, 6, 21; R: 11); Spiculocaulus (H: 3); Skrjabinocaulus (A: 4, 28; R: 7); Orthostrongylus (A: 4; R: 11); Protostrongylus (H: 3; P: 2, 3, 5, 6, 19). Internodes beginning basally are designated 1-12: 1 (A: 1, 4, 8, 27, 28); 2 (A: 6, 18, 28; H: 9); 3 (A: 4, 12, 13, 17, 20, 23); 4 (A: 15, 16, 26; H: 11); 5 (A: 3, 21, 22, 24; H: 5; R: 18); 6 (H: 2, 3, 22); 7 (A: 10); 8 (A: 6, 4; H: 5, 11; R: 8); 9 (A: 3, 7, 22); 10 (A: 19, 25; H: 9); 11 (A: 2, 14); 12 (A: 1,5$)$.

group association for Elaphostrongylinae (with Elaphostrongylus and Parelaphostrongylus) + Muelleriinae (with Muellerius Cameron, 1927 and Cystocaulus Schulz, Orlow, and $\mathrm{Ku}-$ tass, 1933 + Umingmakstrongylus); and (2) Pneumostrongylus Mönnig, 1932 + Varestrongylus Bhalerao, 1932 in a subclade basal to Pneumocaulus Schulz and Andreeva, 1948, Neostrongylus Gebauer, 1932, Spiculocaulus Schulz, Orlow, and Kutass, 1933, Skrjabinocaulus Boev and Sulimov, 1963, Orthostrongylus Dougherty and Goble, 1946, and Prostostrongylus (Fig. 1).

Analysis at the species level yielded a single MPT (76 steps; $\mathrm{CI}=0.582 ; \mathrm{CI}$, excluding uninformative characters $=0.577$; $\mathrm{HI}=0.418 ; \mathrm{RI}=0.759$ ) (Fig. 2) that diagnoses monophyly for the family based on characters 1, 6, 27, and 28 (Fig. 2);
TABLE V. Consistency indices and number of steps on the tree for the 28 characters used in generic- and species-level analyses of Protostrongylidae.*

\begin{tabular}{|c|c|c|c|c|}
\hline \multirow[b]{2}{*}{ Character } & \multicolumn{2}{|c|}{ Generic-level analysis } & \multicolumn{2}{|c|}{ Species-level analysi } \\
\hline & Tree steps & CI & Tree steps & CI \\
\hline 1 & 2 & 1.000 & 2 & 1.000 \\
\hline 2 & 9 & 0.778 & 11 & 0.364 \\
\hline 3 & 8 & 0.500 & 8 & 0.500 \\
\hline 4 & 8 & 0.750 & 7 & 0.714 \\
\hline 5 & 4 & 0.750 & 4 & 0.500 \\
\hline 6 & 6 & 0.667 & 5 & 0.400 \\
\hline 7 & 2 & 0.500 & 2 & 0.500 \\
\hline 8 & 3 & 0.333 & 2 & 0.500 \\
\hline 9 & 3 & 0.333 & 3 & 0.333 \\
\hline 10 & 1 & 1.000 & 1 & 1.000 \\
\hline 11 & 4 & 0.500 & 3 & 0.667 \\
\hline 12 & 1 & 1.000 & 1 & 1.000 \\
\hline 13 & 1 & 1.000 & 1 & 1.000 \\
\hline 14 & 1 & 1.000 & 2 & 0.500 \\
\hline 15 & 1 & 1.000 & 1 & 1.000 \\
\hline 16 & 1 & 1.000 & 1 & 1.000 \\
\hline 17 & 1 & 1.000 & 1 & 1.000 \\
\hline 18 & 2 & 0.500 & 3 & 0.333 \\
\hline 19 & 2 & 1.000 & 2 & 0.500 \\
\hline 20 & 1 & 1.000 & 1 & 1.000 \\
\hline 21 & 2 & 0.500 & 2 & 0.500 \\
\hline 22 & 4 & 0.500 & 5 & 0.400 \\
\hline 23 & 1 & 1.000 & 1 & 1.000 \\
\hline 24 & 1 & 1.000 & 1 & 1.000 \\
\hline 25 & 3 & 0.667 & 3 & 0.667 \\
\hline 26 & 1 & 1.000 & 1 & 1.000 \\
\hline 27 & 1 & 1.000 & 1 & 1.000 \\
\hline 28 & 4 & 1.000 & 4 & 0.750 \\
\hline
\end{tabular}

* Values were calculated using PAUP version 3.1.1.

diagnostics for individual characters are shown in Table V. Homoplasy was associated with 15 characters (parallelism/convergence for characters $2-7,9,11,18,19,21,22$, and 25; reversal for $2,5,8,14,18$, and 28). Two major clades were diagnosed. The first contained 3 subclades with Varestrongylus spp. + Pneumostrongylus calcaratus (Mönnig, 1932) as the sister group for the Elaphostrongylinae + Muelleriinae (Muellerius capillaris (Mueller, 1889), Cystocaulus ocreatus (Railliet and Henry, 1908), and Umingmakstrongylus pallikuukensis). This subclade is diagnosed by 2 synapomorphies including a distally branched spicule shaft (character 8) that was secondarily lost in Elaphostrongylus spp. and a long, divided dorsal ray (character 28). The subclade containing Varestrongylus spp. included an unresolved trichotomy of Varestrongylus pneumonicus Bhalerao, 1932, Varestrongylus sagittatus (Mueller, 1891), and $P$. calcaratus. Basal to these 3 species was Varestrongylus alpenae (Dikmans, 1935). This subclade of 4 species is diagnosed by having ventral rays joined by a long and thin common stalk (character 10). The elaphostrongyline subclade was characterized by 5 synapomorphies including an anteriorly located excretory pore (character 12), an anteriorly located nerve ring (13), spherical eggs (17), a rounded cephalic extremity (20), and a female tail in the form of a blunt cone (23). The muelleriine subclade containing $M$. capillaris, $C$. ocreatus, and $U$. pallikuukensis is diagnosed by a jointed spicule shaft (character 




FIGURE 2. Phylogenetic relationships for selected species of Protostrongylidae Leiper, 1926, particularly those in the genera Varestrongylus Bhalerao, 1932 and Protostrongylus Kamensky, 1905 as inferred by parsimony analysis of morphological characters. Represented is the single most parsimonious tree $(\mathrm{CI}=0.582)$. Character support for terminal taxa and internodes is defined below (nodes are numbered) and includes apomorphy (A) and homoplasy as convergence or parallelism (H) and reversal (R). Terminal taxa are labeled according to specieslevel nomenclature: outgroup, Metastrongylus apri; ingroup: Muellerius capillaris (A: 2; H: 25); Cystocaulus ocreatus (H: 2); Umingmakstrongylus pallikuukensis (R: 6); Elaphostrongylus cervi (H: 25; R: 8); Parelaphostrongylus odocoilei (H: 3, 22); Pneumostrongylus calcaratus (A: 3; H: 9); Varestrongylus alpenae (without diagnostic characters); Varestrongylus sagittatus (without diagnostic characters); Varestrongylus pneumonicus (A: 2); Neostrongylus linearis (H: 2, 7, 21); Pneumocaulus kadenazii (A: 3, 22; H: 2); Skrjabinocaulus sofievi (A: 4, 28); Orthostrongylus macrotis (A: 4; R: 11; H: 19); Spiculocaulus leuckarti (R: 14); Protostrongylus hobmaieri (A: 2); Protostrongylus rufescens (R: 2); Protostrongylus raillieti (without diagnostic characters); Protostrongylus rushi (without diagnostic characters); Protostrongylus stilesi (without diagnostic characters); Protostrongylus boughtoni (H: 2, 19); and Protostrongylus pulmonalis (without diagnostic characters). Internodes beginning basally are designated 1-19: 1 (A: 1, 6, 27, 28); 2 (A: 8, 28); 3 (A: 10; H: 2, 3, 22); 4 (H: 4; R: 6, 28); 5 (H: 9, 18); 6 (A: $12,13,17,20,23) ; 7$ (A: 4, 15, 16, 26; H: 11); 8 (A: 3, 24; H: 4, 5, 21, 22; R: 18); 9 (A: 3, 4; H: 5, 22); 10 (A: 4, 6; H: 11); 11 (A: 14 , 25; H: 9); 12 (A: 1, 5; H: 7); 13 (A: 3); 14 (H: 2); 15 (A: 3); 16 (A: 2); 17 (R: 6); 18 (R: 5); 19 (H: 18).

15), ctenidia-like ribs on the spicules (16), and a consistently trilobed dorsal ray (26).

The second major clade (Fig. 2) contained $N$. linearis, $P$. kadenazii, and $S$. sofievi as species basal to a group consisting of Orthostrongylus macrotis (Dikmans, 1931) plus a subclade with 7 species of Protostrongylus and S. leuckarti and is weakly diagnosed by the structure of the crura and the telamon (characters 3 and 4). The $O$. macrotis + Protostrongylus subclade is diagnosed by first-stage larvae with spiked tails (character 1). Within the Protostrongylus subclade, Protostrongylus boughtoni Goble and Dougherty, 1943 and Protostrongylus pulmonalis (Frölich, 1802) are basal and putative sister species. Two additional groups are diagnosed: (1) Protostrongylus hobmaieri (Schulz, Orlow, and Kutass, 1933) and S. leuckarti are sister species; and (2) Protostrongylus stilesi Dikmans, 1931 is the sister for Protostrongylus rushi Dikmans, 1937, Protostrongylus raillieti (Schulz, Orlow, and Kutass, 1933), and Protostrongylus rufescens (Leuckart, 1865).

Based on CI values for individual characters (Table V), characters $1,10,12,13,15-17,20,23,24,26$, and 27 were the most informative $(C I=100 \%)$, whereas characters $2,6,9,18$, and 22 had low CI values $(<50 \%)$. These were relatively consistent in both the generic and species-level analyses.

The major clades and subclades were diagnosed in both generic and species-level analyses, although relative position in respective trees was variable (Figs. 1,2). Both analyses placed the Muelleriinae and Elaphostrongylinae as sister groups. $\mathrm{Va}$ restrongylus + Pneumostrongylus, however, were either the sister of the Muelleriinae + Elaphostrongylinae (Fig. 2) or excluded from this subclade to be placed basal to the remaining protostrongylid genera (Fig. 1). Protostrongylus was consistently placed in the crown of both trees.

When the Crenosomatidae or Skrjabingylidae were used as outgroups either together or independent from the Metastrongylidae, results were characterized by a high level of instability and ambiguity. Multiple outgroups did not aid in resolution of the tree(s), and results of these analyses (not shown) were highly inconsistent, both in the numbers of MPTs and in the relationships postulated among genera and species. Additionally, inclusion or exclusion of species from the analysis influenced the structure of the major clades, subfamily groupings, e.g., subclades, and in species relationships as depicted in Figure 2. In contrast, stability in tree topology was observed with the Metastrongylidae designated as the sole outgroup in both generic and species-level analyses.

\section{Parasite-host relationships}

Host-group taxa at the level of family, subfamily, tribe, or species were mapped onto the parasite phylogeny derived from species-level analysis (Fig. 3). Mapping and optimization (CI $=0.82$ ) indicates the following: (1) Cervidae are basal hosts for protostrongylids; (2) a minimum of 3 independent colonization events from cervids to the Caprinae (including the Caprini and Rupicaprini) are postulated; and (3) additional hostswitching is recognized with respect to the distributions of $U$. pallikuukensis, $P$. calcaratus, $O$. macrotis, and $P$. hobmaieri. The structure of this tree, relative to the species of protostrongylids examined, suggests that distinct groups of Protostrongylus spp. occur in Caprini and in Lagomorpha, but basal host associations cannot yet be resolved for this assemblage (Fig. 3 ). These overall relationships were consistent with mapping of host groups onto the generic-level phylogeny (not shown).

\section{DISCUSSION}

\section{Phylogeny for Protostrongylidae}

Monophyly for the Protostrongylidae is corroborated by the current analysis. The putative subclades diagnosed in the present analysis (Figs. 1,2) correspond in general to the subfam- 




FIGURE 3. Phylogenetic hypothesis for selected species of Protostrongylidae Leiper, 1926 showing distribution of ruminant definitive hosts mapped and optimized on the parasite cladogram $(\mathrm{CI}=0.82)$. Hosts are as follows: $\mathrm{A}=$ Alcelaphinae and Antelopinae; $\mathrm{An}=$ Antilocapra americana $\mathrm{Ca}=$ Caprini; $\mathrm{Ce}=$ Cervidae; $\mathrm{L}=$ Lagomorpha; $\mathrm{Ov}=$ Ovibos moschatus; and $\mathrm{R}=$ Rupicaprini. Putative ancestral hosts are Cervidae, and the distribution of protostrongylids in bovids of the tribes Caprini and Rupicaprini is compatible with independent colonization in some instances followed by secondary cospeciation. The distribution in Lagomorpha resulted in colonization from a ruminant source. This distribution is consistent with a complex history of cospeciation and colonization.

ilies outlined by Boev (1975) and serve to validate this classification in part. Representatives of the Elaphostrongylinae, Muelleriinae, and Protostrongylinae were all monophyletic groups. In contrast, the Neostrongylinae was not supported as there was no sister-group relationship between $N$. linearis and $O$. macrotis. The phylogenetic position of $P$. kadenazii was also uncertain. It did not group with members of the Varestrongylinae and occurred basal to the subclade containing members of the Protostrongylinae.

Several genera in the classification of Boev (1975) appear to be paraphyletic based on results of phylogenetic studies outlined herein. The occurrence of $P$. calcaratus in the Varestrongylus subclade indicates that Pneumostrongylus is very closely related to the latter and could be synonymized with Varestrongylus. Both genera were originally named and described in 1932 (Mönnig [1932] for Pneumostrongylus and Bhalerao [1932] for Varestrongylus). Boev (1975) distinguished Pneumostrongylus from Varestrongylus by the proximal part of the spicules, or manubrium, which was well defined in the former. The crura of the gubernaculum in Pneumostrongylus are also distinct from those observed in species of Varestrongylus. Al- though the spicule structure may, as an autapomorphy, distinguish Pneumostrongylus from Varestrongylus, this feature as well as the morphology of the crura are apparently not informative as phylogenetic characters in diagnosing the 2 genera. The synapomorphies for the subclade indicate paraphyly of $\mathrm{Va}$ restrongylus if Pneumostrongylus is excluded, suggesting a necessity to modify the current classification and to reduce the latter as a synonym (see Boev, 1975).

Pneumostrongylus has been a confusing taxon in protostrongylid systematics as many nematodes currently classified in other genera have, in the past, been referred to this genus. Varestrongylus alpenae from the lungs of the white-tailed deer Odocoileus virginianus Zimmermann was originally described as a species of Pneumostrongylus. Similarly, P. tenuis was originally described by Dougherty (1945) as a species of Pneumostrongylus. Parelaphostrongylus was not erected until 1950 (Boev and Schulz, 1950), and Pneumostrongylus would have been the most accurate diagnosis at the time of Dougherty's original description. Dougherty and Goble (1946) erected Leptostrongylus to accommodate $V$. alpenae and Varestrongylus capreoli (Stroh and Schmid, 1938). The classification of Boev (1975) appears to be most commonly used at present. Here, Pneumostrongylus is restricted to 2 species, $P$. calcaratus and Protostrongylus cornigerus Ortlepp, 1962.

The grouping of S. leuckarti with the Protostrongylus subclade indicates that Protostrongylus may also be paraphyletic if Spiculocaulus is excluded. Boev (1975) included Spiculocaulus with Protostrongylus in the Protostrongylinae. The main difference between the 2 genera, as described by Boev and others (Dougherty and Goble, 1946; Anderson, 1978) is the much longer, filiform spicules in Spiculocaulus. The characters used in our analysis indicate that Spiculocaulus may be a synonym of Protostrongylus despite the autapomorphic feature of the longer spicules.

Similarly, Orthostrongylus was erected to separate $O$. $m a$ crotis from other species of Protostrongylus because of the elaborately developed telamon in the former (Dougherty and Goble, 1946). Although we hypothesize that $O$. macrotis is basal to the Protostrongylus subclade, it is likely that the only species in this genus, $O$. macrotis, could be classified in Protostrongylus, as it was originally named by Dikmans (1931). Our phylogenetic hypotheses do not correspond to the classification of Boev (1975), who grouped Orthostrongylus with Neostrongylus in the Neostrongylinae. The key to subfamilies provided by Boev (1975) indicates that the spicules are distinctly unequal in the Neostrongylinae. The spicules are not distinctly unequal in $O$. macrotis. The complex form of the telamon in both genera has also been used to group them into 1 subfamily. This is likely a convergent feature as the morphology of the telamon differs greatly between these 2 taxa.

Evidence for the monophyly of the elaphostrongyline subclade is based on an extensive suite of synapomorphic characters. The predilection site for nervous or skeletal muscle tissue rather than the lungs, bronchi, or bronchioles (e.g., Anderson, 1992; Hemmingsen et al., 1993) may have led to selection and structural modification as the elaphostrongylines became adapted to their unique habitat.

It has been postulated by various authors that percutaneous modes of transmission are primitive among nematode parasites of vertebrates; in the Metastrongyloidea, when maturation of 
nematodes occurred at an earlier stage in their tissue migration, the parasites were able to colonize deep tissue sites (Adamson, 1986; Durette-Desset et al., 1994). Members of the metastrongyloid Skrjabingylidae parasitize the sinuses of mustelids. These have been considered to be a group that became isolated in a specific site in the host, whereas other taxa colonized the lungs (Anderson, 1982). The Elaphostrongylinae have also become specialized in a nonpulmonary site, although the evolutionary effects of competition from other metastrongyloids in the lungs are unclear.

\section{Additional phylogenetic characters}

The precise functions of the structural characters in the Elaphostrongylinae and in other taxa are presently unknown. Unfortunately, it was not possible to obtain additional suitable morphological data for the cephalic papillae and stoma in each of the ingroup taxa. Although en face observations using light microscopy are useful, more detail is observable by scanning electron microscopy (SEM). Despite the availability of SEM descriptions for 3 genera (Gibbons et al. [1991]; Carreno and Lankester [1993] for Elaphostrongylus and Parelaphostrongylus; Hoberg et al. [1995] for Umingmakstrongylus), there are no data for most other genera. Obvious differences are apparent between Umingmakstrongylus and the Elaphostrongylinae, and our preliminary observations on other taxa (data not shown) indicate considerable differences among some species in Protostrongylus as well as in other genera (e.g., character 19). There is clearly also a need for SEM studies of first-, second-, and third-stage larvae, with emphasis on the morphology of the tail.

There are presently no DNA sequences available for protostrongylid nematodes that can be used in phylogenetic analysis. However, preliminary analyses using protein electrophoresis have indicated differences between Protostrongylus spp. and other lungworms (Cutillas et al., 1995). Similarly, the use of isoelectric focusing has demonstrated similar isoelectric points between adults and larvae of presumed single species (Steen et al., 1994). Recently, internal-transcribed spacer (ITS) sequences were used to distinguish several Metastrongylus spp. in a sympatric population (Leignel et al., 1997). In the latter study, ITS sequences were used to avoid the use of morphological characters to identify phenotypically similar species. Similar sequences would also be useful in analyses of the Protostrongylidae, particularly within the genus Protostrongylus.

\section{Supraspecific taxa or species in phylogenetic analysis}

The major clades and subclades were diagnosed in both generic and species-level analyses, although their relative position in respective trees was variable (Figs. 1,2). Matrices used to explore relationships were largely similar (Tables III, IV) but differed in using supraspecific (Fig. 1) versus species-level taxa (Fig. 2) as terminal groups in respective analyses. This influenced character coding, particularly at the generic level where multistate taxa (Protostrongylus and Varestrongylus) in this analysis were coded as polymorphic for a limited number of characters (Table III).

Recent studies have discussed the problems and the range of proposed solutions associated with examining relationships of higher-level or supraspecific taxa (e.g., Yeates, 1995; Binida-
Emonds et al., 1998; Wiens, 1998). Although conclusions and recommendations from these studies are not entirely in agreement, it is clear that the strength of phylogenetic hypotheses is dependent on inclusion of data for variable characters and their distribution within taxa (Wiens, 1998).

Whereas a complete species-level analysis might be preferred, it is also clear that this is often not practical or possible. When supraspecific taxa are used as terminals in phylogenetic analysis, methods that infer ancestral states, e.g., the IAS method, for polymorphic (multistate) taxa are preferable to those that employ estimates of primitive or derived states or include polymorphism and may provide more accurate results (Yeates, 1995; Wiens, 1998). Binida-Emonds et al. (1998) found that such an ancestral method provided a strong and justified alternative approach to using exemplars ( 1 or more species-level representatives of a higher taxon) in estimates of higher-level phylogeny. In contrast, Wiens (1998) advocated using species as terminals (splitting of higher taxa) whenever possible and that methods using higher-level taxa alone performed relatively poorly based on a simulation approach to examining the problems of coding and taxon representation.

The current study used designation of polymorphism in generic-level taxa (Table III) because previous estimates of higher-level phylogeny within the Protostrongylidae were not available. Thus, within the context of ingroup phylogeny, ancestral states could not be estimated (Wiens, 1998). This may have influenced the topology of the MPT recovered (Fig. 1), although the major subclades are largely consistent with the species-level evaluation. Whereas the protostrongyles should eventually represent a group in which complete analysis of species is tractable, as noted below, the availability of high-quality specimens in museum collections is limited. Additionally, inclusion or exclusion of species from the analysis (Table IV; Fig. 2) influenced the structure of the major clades, subfamily groupings, e.g., subclades, and in relationships for species, often yielding highly ambiguous results. Thus, it is clear that an exemplar method that uses single or limited numbers of species to represent large higher-level taxa may result in erroneous estimates of relationship, and phylogenetic structure will vary as a function of the species included or excluded from the analysis (Binida-Emonds et al., 1998; Wiens, 1998).

\section{Parasite-host coevolution}

Putative patterns of parasite-host coevolution (collectively cospeciation and coadaptation) can be elucidated initially by examining host-distribution relative to a phylogeny for a parasitic group (e.g., Brooks and McLennan, 1993). This has been explicitly examined for the Elaphostrongylinae and their cervid hosts (Platt, 1984; Carreno and Lankester, 1994), but critical coevolutionary studies of other protostrongylids are lacking. Protostrongylids are widespread in Cervidae, Caprini, and Lagomorpha but rare among such ruminant groups as the Rupicaprini, Alcelaphinae, and Antelopinae, and are unknown in suids, tragulids, and giraffids.

Mapping of host taxa onto the species-level phylogeny for the Protostrongylidae unequivocally revealed Cervidae as the basal hosts for the family and supports a history of cospeciation involving the elaphostrongylines (see Platt, 1984) and other genera (Fig. 3). Colonization of bovids of the subfamily Ca- 
prinae and those in the tribes Caprini and Rupicaprini from a cervid source is postulated with respect to the Muelleriinae, $V$. pneumonicus, and $N$. linearis. Further, host-switching appears to be compatible with the occurrence of Muellerius in rupicaprine hosts, $U$. pallikuukensis in Ovibos moschatus (Zimmermann), $P$. calcaratus in African Antelopinae and Alcelaphinae, O. macrotis in Antilocapra americana (Ord), and P. hobmaieri in Rupicaprini.

Patterns of cospeciation are also suggested by the distribution of Protostrongylus in either Lagomorpha or in the Caprini, but basal associations for this subclade are unresolved in the context of the current study (Fig. 3). The putative sister-group relationship of $P$. pulmonalis and $P$. boughtoni, the only 2 species examined in this study that parasitize lagomorphs, may be indicative of cospeciation with a distinct group in Protostrongylus. A more inclusive analysis of the genus, including other species known to parasitize lagomorphs is necessary, e.g., Protostrongylus cuniculorum (Joyeux and Gaud, 1946) Schulz and Kadenazii, 1949; Protostrongylus oryctolagi Babos, 1955; Protostrongylus tauricus Schulz and Kadenazii, 1949; Protostrongylus terminalis (Passerini, 1884) Schulz, Orlow, and Kutass, 1933; and Protostrongylus kamenskyi Schulz, 1930. There are few suitable museum specimens available for these species as well as for other protostrongylids, further constraining the possibility of a more comprehensive analysis.

Cospeciation of protostrongylids following independent colonization of the Caprini may have involved both species of Protostrongylus (including Spiculocaulus) and those in the Muelleriinae (Fig. 3). Host-specificty appears limited, however, with many species being reported from a wide range of caprine hosts (Boev, 1975), an observation that will confound clear resolution of a history for diversification of protostrongylids in wild sheep, goats, and allied bovids.

Although clearly associated basally with the Caprini, the host associations for constituent genera and species of the Muelleriinae continue to be resolved incompletely (see Hoberg et al., 1995). The current tree suggests that the occurrence of Muellerius in rupicaprine hosts represents colonization. Understanding the history of Umingmakstrongylus, however, is in part linked to resolution of phylogenetic relationships among the Caprini and Rupicaprini and the placement of $O$. moschatus (Thenius, 1980; Pasitschniak-Arts et al., 1994; Hoberg et al., 1995; Groves and Shields, 1996). Muskox are not considered to be close to the Caprini (wild sheep and goats, hosts for Cystocaulus, the sister group of Umingmakstrongylus) based on the most recent phylogenetic studies of the Caprinae (Groves and Shields, 1996). Alternative evidence has suggested an association with the takin (Budorcus taxicolor Hodgson), considered by some as the nearest extant relative of muskoxen with placement in the tribe Ovibovini (Pasitschniak-Arts et al., 1994). As indicated by Hoberg et al. (1995), however, the occurrence of a species of Varestrongylus in the takin provides no phylogenetic information relative to host phylogeny or the occurrence of Umingmakstrongylus in muskoxen. Hypotheses presented by Hoberg et al. (1995) for colonization of muskoxen from a caprine source, e.g., wild species of Ovis Linnaeus, during the Pleistocene are not refuted.

The Protostrongylidae evolved primarily in ruminants (Dougherty, 1949), and our results further support Dougherty's hypothesis that parasitism of lagomorphs was a host-switching event that occurred from a ruminant ancestor. Caprine hosts (particularly sheep and goats) are very common for various distantly related protostrongylids, and 2 independent lineages appear to have coevolved with this group; cervids are also hosts of diverse genera. Recognition of a basal association for Cervidae and protostrongyles, however, still does not completely address the broader coevolutionary history for ruminants and these lungworms. This situation exists because of the array of largely dissimilar hypotheses that have been developed for the phylogeny and interfamilial relationships for the pecoran ruminants that serve as the primary hosts for genera and species of protostrongyles (e.g., Groves and Grubb, 1987; Janis and Scott, 1988; Gentry and Hooker, 1988; Kraus and Miyamoto, 1991). Radiation of the pecoran ruminants is estimated to have occurred rapidly between 23 and 28 million years ago (Kraus and Miyamoto, 1991), and origins of the protostrongyles may be eventually linked to this diversification assuming evidence for a history of coevolution.

Further confounding development of a comprehensive hypothesis for host-parasite coevolution, however, is the recognition that data for host occurrence and specificity may be limited in some genera. Few cross-infection experiments have been undertaken to determine host specificity, and it is not known whether some species can infect distantly related hosts. For example, the initial description of Protostrongylus coburni Dikmans, 1935 was based on parasites found in the lungs of whitetailed deer ( $O$. virginianus). The illustration of the first-stage larvae, however, showed dorsal-spined forms not characteristic of the genus Protostrongylus and were likely those of Varestrongylus alpenae. Larvae with the spike-shaped tail characteristic of Protostrongylus spp. were not shown (Dikmans, 1935). In a recent examination of parasites described as $P$. coburni (USNPC lot 46229 but not the types 34065 ), we could not distinguish these parasites from $P$. boughtoni of snowshoe hares (unpublished observations).

Thus, the possibility of less strict host specificity than has previously been known should be further investigated in the Protostrongylidae. This, and more complete treatment of species of Protostrongylus and other genera will promote a refined understanding of the evolutionary history of these significant mammalian parasites.

\section{ACKNOWLEDGMENTS}

We are grateful to Allen Shostak, Department of Zoology, University of Alberta, for providing several lots of specimens from the University of Alberta Parasite Collection. Judith Price, Canadian Museum of Nature, Ottawa, Canada, also lent us several specimens from her institution. M. A. Hayes, Department of Pathobiology, University of Guelph, kindly provided the use of his MacIntosh computer to R.A.C. for initial analysis using PAUP 3.1.1. Thoughtful discussions with John R. Barta, Department of Pathobiology, University of Guelph, contributed greatly to the manuscript.

\section{LITERATURE CITED}

AdAmson, M. L. 1986. Modes of transmission and evolution of life histories in zooparasitic nematodes. Canadian Journal of Zoology 64: 1375-1384.

ANDERSON, R. C. 1964. Neurologic disease in moose infected experi- 
mentally with Pneumostrongylus tenuis from white-tailed deer. Pathologia Veterinaria 1: 289-322.

- 1971. Neurologic disease in reindeer (Rangifer tarandus tarandus) introduced into Ontario. Canadian Journal of Zoology 49: 159-166.

1978. Keys to the genera of the superfamily Metastrongyloidea, no. 5. In CIH keys to the nematode parasites of vertebrates, R. C. Anderson, A. G. Chabaud, and S. Willmott (eds.). Commonwealth Agricultural Bureaux, Farnham Royal, U.K., p. 1-40.

1982. Host-parasite relations and evolution of the Metastrongyloidea (Nematoda). Mémoires du Muséum National d'Histoire Naturelle, Série A, Zoologie 123: 129-133.

- 1992. Nematode parasites of vertebrates, their development and transmission. C.A.B. International, Wallingford, U.K., 578 p.

BHALERAO, G. D. 1932. On some nematode parasites of goats and sheep at Muktesar. Indian Journal of Veterinary Science and Animal Husbandry 2: 242-254.

Binida-Emonds, O. R. P., H. N. BRyant, and A. P. Russell. 1998. Supraspecific taxa as terminals in cladistic analysis: Implicit assumptions of monophyly and a comparison of methods. Biological Journal of the Linnean Society 64: 101-133.

Boev, S. N. 1975. Protostrongylids. Fundamentals of nematology, Vol. 25. Helminthological Laboratory, Academy of Sciences of the USSR, Moscow. [English translation by the U.S. Department of Agriculture, Washington, D.C., and Amerind Publishing Co., New Delhi, 1984, 338 p.]

- AND R. S. SCHULZ. 1950. [Reconstruction of the systematics of the nematode family Protostrongylidae Leiper, 1926.] Doklady Akademiia Nauk SSSR 70: 355-358. [In Russian.]

- AND A. B. Sulimov. 1963. Skrjabinocaulus sofievi, n.g., n.sp., a new nematode from the lungs of Capreolus capreolus. Helminthologia 4: 109-114.

Brooks, D. R., AND D. A. McLennan. 1993. Parascript, parasites and the language of evolution. Smithsonian Institution Press, Washington, D.C., 429 p.

Brown, T. T., H. E. Jordan, AND C. N. Demorest. 1978. Cerebrospinal parelaphostrongylosis in llamas. Journal of Wildlife Diseases 14: 441-444.

Carreno, R. A., and M. W. Lankester. 1993. Additional information on the morphology of the Elaphostrongylinae (Nematoda: Protostrongylidae) of North American Cervidae. Canadian Journal of Zoology 71: 592-600.

$\longrightarrow$, AND $\longrightarrow$ 1994. A re-evaluation of the phylogeny of Parelaphostrongylus Boev and Schulz, 1950 (Nematoda: Protostrongylidae). Systematic Parasitology 28: 145-151.

Castañon Ordoñez, L., M. Cordero del Campillo, and F. A. Rojo VAZQUEZ. 1984. Migration and growth of Neostrongylus linearis (Marotel, 1913) Gebauer, 1932, in sheep. Veterinary Parasitology 15: $271-284$.

Costantini, R., M. T. Manfredi, A. Iori, And A. Pacetti. 1990. Protostrongylus pulmonalis from hares (Lepus europaeus) in Italy. Parassitologia 32: 353-357.

Cutillas, C., C. Espina, M. Spakulova, and P. Arias. 1995. Differential diagnosis of lung nematode parasites from livestock by electrophoretic techniques. International Journal for Parasitology 25: 215-220.

Demartini, J. C., AND R. B. Davies. 1977. An epizootic of pneumonia in captive bighorn sheep infected with Muellerius sp. Journal of Wildlife Diseases 13: 117-124.

Dikmans, G. 1931. Two new lungworms from North American ruminants and a note on the lungworms of sheep in the United States. Proceedings of the United States National Museum 79: 1-4.

. 1935. Two new lungworms, Protostrongylus coburni n. sp., and Pneumostrongylus alpenae, n. sp. from the deer, Odocoileus virginianus, in Michigan. Transactions of the American Microscopical Society 54: $138-144$.

DougherTy, E. C. 1945. The nematode lungworms (suborder Strongylina) of North American deer of the genus Odocoileus. Parasitology 36: 199-208.

- 1949. The phylogeny of the nematode family Metastrongylidae Leiper (1909): A correlation of host and symbiote evolution. Parasitology 39: 222-234.

- AND F. C. GoBle. 1946. The genus Protostrongylus Kamenskii,
1905 (Nematoda: Metastrongylidae), and its relatives: Preliminary note. Journal of Parasitology 32: 7-16.

DuRETTE-DESSET, M.-C. 1985. Trichostrongyloid nematodes and their vertebrate hosts: Reconstruction of the phylogeny of a parasitic group. Advances in Parasitology 24: 239-306.

- I. BeVEridge, AND D. M. SpRATT. 1994. The origins and evolutionary expansion of the Strongylida (Nematoda). International Journal for Parasitology 24: 1139-1165.

Gebauer, O. 1932. Zur Kenntnis der Parasitenfauna der Gemse. Zeitschrift für Parasitenkunde 4: 147-219.

Gentry, A. W., AND J. J. Hooker. 1988. The phylogeny of the Artiodactyla. In The phylogeny and classification of the tetrapods, Systematics Association Special Volume 35B, M. J. Benton (ed.). Clarendon Press, Oxford, U.K., p. 235-272.

Gibbons, L. M., O. Halvorsen, and G. Stuve. 1991. Revision of the genus Elaphostrongylus Cameron (Nematoda, Metastrongyloidea) with particular reference to species of the genus occurring in Norwegian cervids. Zoologica Scripta 20: 15-26.

Groves, C. P., AND P. GruBB. 1987. Relationships of the living deer. In Biology and management of the Cervidae, C. M. Wemmer (ed.). Smithsonian Institution Press, Washington, D.C., p. 21-59.

Groves, P., AND G. F. SHIELDS. 1996. Phylogenetics of the Caprinae based on cytochrome b sequence. Molecular Phylogenetics and Evolution 5: 467-476.

Guthery, F. S., S. L. BEASOM, AND L. JonEs. 1979. Cerebrospinal nematodiasis caused by Parelaphostrongylus tenuis in Angora goats in Texas. Journal of Wildlife Diseases 15: 37-42.

HANDELAND, K., AND H. S. NoRBERG. 1992. Lethal cerebrospinal elaphostrongylosis in a reindeer calf. Journal of Veterinary Medicine Series B 39: 668-671.

- - AND A. SKORPING. 1992. Experimental cerebrospinal elaphostrongylosis (Elaphostrongylus rangiferi) in goats: II. Pathological findings. Journal of Veterinary Medicine Series B 39: 713-722.

, AND —. 1993. Experimental cerebrospinal elaphostrongylosis (Elaphostrongylus rangiferi) in goats: I. Clinical observations. Journal of Veterinary Medicine Series B 40: 141-147.

Hemmingsen, W., O. Halvorsen, and A. Skorping. 1993. Migration of adult Elaphostrongylus rangiferi (Nematoda: Protostrongylidae) from the spinal subdural space to the muscles of reindeer (Rangifer tarandus). Journal of Parasitology 79: 728-732.

Hibler, C. P., T. R. SPRAKeR, AND E. T. ThORNE. 1982. Protostrongylosis in bighorn sheep. In Diseases of wildlife in Wyoming, 2nd ed., E. T. Thorne, N. Kingston, W. R. Jolley, and R. C. Bergstrom (eds.). Wyoming Game and Fish Department, Laramie, Wyoming, p. 208213.

Hoberg, E. P., AND J. R. Lichtenfels. 1994. Phylogenetic systematic analysis of the Trichostrongylidae (Nematoda), with an initial assessment of coevolution and biogeography. Journal of Parasitology 80: $976-996$.

, L. Polley, A. GunN, AND J. S. Nishi. 1995. Umingmakstrongylus pallikuukensis gen. nov. et sp. nov. (Nematoda: Protostrongylidae) from muskoxen, Ovibos moschatus, in the central Canadian Arctic, with comments on biology and biogeography. Canadian Journal of Zoology 73: 2266-2282.

JANIS, C. M., AND K. M. SCOTT. 1988. The phylogeny of the Ruminantia (Artiodactyla, Mammalia). In The phylogeny and classification of the tetrapods, Systematics Association Special Volume 35B, M. J. Benton (ed.). Clarendon Press, Oxford, U.K., p. 273-282.

Kraus, F., and M. M. MiYamoto. 1991. Rapid cladogenesis among the pecoran ruminants: Evidence from mitchondrial DNA sequences. Systematic Zoology 40: 117-130.

KreIS, H. A. 1944. Beiträge zur Kenntnis parasitischer Nematoden. XI. Neue parasitische Nematoden. Revue Suisse de Zoologie 51: 227 252.

Krogdahl, D. W., J. P. Thilsted, And S. K. Olsen. 1987. Ataxia and hypermetria caused by Parelaphostrongylus tenuis infection in llamas. Journal of the American Veterinary Medical Association 190: 191-193.

LANKESTER, M. W., AND D. FoNG. 1989. Distribution of elaphostrongyline nematodes (Metastrongyloidea: Protostrongylidae) in Cervidae and possible effects of moving Rangifer spp. into and within North America. Alces 25: 133-145.

Leignel, V., J. F. Humbert, AND L. Elard. 1997. Study by ribosomal 
DNA ITS 2 sequencing and RAPD analysis on the systematics of four Metastrongylus species (Nematoda: Metastrongyloidea). Journal of Parasitology 83: 606-611.

LiChTENFELS, J. R. 1987. Phylogenetic inference from adult morphology in the Nematoda; with emphasis on the bursate nematodes, the Strongylida; advancements (1982-1985) and recommendations for further work. In Parasitology-Quo Vadit? Proceedings of the Sixth International Congress of Parasitology, M. J. Howell (ed.). Pergamon Press, Oxford, U.K., p. 269-279.

MAdDISON, W. P., AND D. R. MAdDISON. 1992. MacClade: Analysis of phylogeny and character evolution, version 3.0. Computer Program. Sinauer and Associates, Sunderland, Massachusetts, 398 p.

Mansfield, L. S., H. R. Gamble, J. S. BaKer, AND J. R. Lichtenfels. 1993. Lungworm infection in a sheep flock in Maryland. Journal of the American Veterinary Medical Association 202: 601-606.

MönNIG, H. O. 1932. New strongylid nematodes of antelopes (preliminary notes). Journal of the South African Veterinary Medical Association 3: 171-175.

Nettles, V. F., A. K. Prestwood, And R. D. Smith. 1977. Cerebrospinal parelaphostrongylosis in fallow deer. Journal of Wildlife Diseases 13: $440-444$.

PAJERSKY, A. 1995. Nodular changes in lungs of hare caused by parasite Protostrongylus commutatus (Diesing, 1851). Helminthologia 32: 209-213.

Pasitschniak-Arts, M., P. Flood, S. M. Schmutz, and B. Seidel. 1994. A comparison of G-band patterns of the muskox and takin and their evolutionary relationship to sheep. Journal of Heredity 85: 143147.

PLATT, T. R. 1984. Evolution of the Elaphostrongylinae (Nematoda: Metastrongyloidea: Protostrongylidae) parasites of cervids (Mammalia). Proceedings of the Helminthological Society of Washington 51: 196-204.

Prosl, H., AND E. Kutzer. 1980. Zur Pathologie des Elaphostrongylusbefalles beim Rothirsch (Cervus elaphus hippelaphus). Monatshefte für Veterinärmedizin 35: 151-153.

PRYADKO, E. I. 1984. [The genesis of the protostrongylid fauna.] In Gel'minty sel'skokhozyaistvennykh I okhotnich 'epromyslovykh zhivotnykh, M. D. Sonin (ed.). Izdatel'stvo Nauka, Moscow, Russia, p. 53-76.

Rojo-Vazquez, F. A., and M. Cordero del Campillo. 1974. Le cycle biologique de Neostrongylus linearis (Marotel, 1913) Gebauer, 1932. Annales de Parasitologie Humaine et Comparée 49: 685699.

Roneus, O., AND M. NoRdKvist. 1962. Cerebrospinal and muscular nematodiasis (Elaphostrongylus rangiferi) in Swedish reindeer Acta Veterinaria Scandinavica 3: 201-225.

SAUERLÄNDER, R. 1988. Experimental infection of sheep and goats with Muellerius capillaris (Protostrongylidae, Nematoda). Journal of Veterinary Medicine Series B 35: 525-548.

SChulz, R. E., AND N. K. ANDREEVA. 1948. Morphology and biology of a new nematode from the musk deer. Doklady Akademiia Nauk SSSR 62: 841-843. [In Russian.]

, I. W. Orlow, and A. J. Kutass. 1933. Zur Systematik der Subfamilie Synthetocaulinae Skrj. nebst Beschreibung einiger neuer Gattungen und Arten. Zoologischer Anzeiger 102: 303-310.

Stéen, M., S. Persson, And L. HaJdu. 1994. Protostrongylidae in Cervidae and Ovibos moscatus: A clustering based on isoelectric focusing on nematode body proteins. Applied Parasitology 35: 193206.

SVARC, R. 1984. Pulmonary nematodes of the chamois Rupicapra rupicapra tatrica Blahout, 1971. 1. Pathomorphological picture of lungs during the development of worms into the adult stage. Helminthologia 21: $141-150$

SwOFFORD, D. L. 1993. PAUP: Phylogenetic analysis using parsimony, version 3.1. Formerly distributed by Illinois Natural History Survey, Champaign, Illinois, $257 \mathrm{p}$.

THENIUS, E. 1980. Grundzüge der Faunen und Verbreitungsgeschichte der Säugetiere. Gustav Fischer Verlag, Stuttgart.

TyleR, G. V., C. P. Hibler, AND A. K. Prestwood. 1980. Experimental infection of mule deer with Parelaphostrongylus tenuis. Journal of Wildlife Diseases 16: 533-540.

WIENS, J. J. 1998. The accuracy of methods for coding and sampling higher-level taxa for phylogenetic analysis: A simulation study. Systematic Biology 47: 397-413.

YEATES, D. K. 1995. Groundplans and exemplars: Paths to the tree of life. Cladistics 11: 343-357. 